\title{
Structural Integrity Assessment of Weld for Joining Waveguide to Annular Linear Induction Pump Subjected to Vibration
}

\author{
Ashish Kumar, Y.V. Nagaraja Bhat, B.K. Sreedhar, S.I. Sundar Raj, V.Prakash, P. Selvaraj \\ Indira Gandhi Centre for Atomic Research, Kalpakkam, Tamil Nadu-603102, India. \\ ashishkuman@igcar.gov.in,yvnb@igcar.gov.in,bksd@igcar.gov.in,sisn@igcar.gov.in
}

\begin{abstract}
Annular Linear Induction Pump (ALIP) is employed for low flow rate pumping of liquid metals because of its maintenance free operation. In order to monitor pump vibration during operation, a waveguide with accelerometer combination is employed. The waveguide is a Stainless Steel (SS) rod of $300 \mathrm{~mm}$ length and $20 \mathrm{~mm}$ diameter which is provided with a threaded provision at one end for mounting the accelerometer. The other end of the waveguide is welded to the shell of the ALIP of $3 \mathrm{~mm}$ thickness. These waveguides are to be attached to the ALIP in different orientations. The weld connecting the waveguide to the shell of ALIP is subjected to fatigue loading caused due to pump vibration. This paper discusses the analysis carried out to determine the fatigue life of the weld using ASME SECTION VIII DIVISION 2.
\end{abstract}

KEYWORDS. ALIP; vibration; waveguide; weld; fatigue.

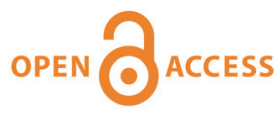

Citation: Kumar, A., Bhat, Y.V.N., Sreedhar, B.K., Sundar Raj, S.I., Prakash, V., Selvaraj, P., Structural Integrity Assessment of Weld for Joining Waveguide to Annular Linear Induction Pump Subjected to Vibration, Frattura ed Integrità Strutturale, 49 (2019) 515-525.

Received: 29.11 .2018

Accepted: 04.06.2019 Published: 01.07.2019

Copyright: (C) 2019 This is an open access article under the terms of the CC-BY 4.0, which permits unrestricted use, distribution, and reproduction in any medium, provided the original author and source are credited.

\section{INTRODUCTION}

\footnotetext{
A nnular linear Induction Pump (ALIP) is used to circulate liquid metals at low flow rates. These pumps are used because they are maintenance free due to the absence of moving parts. However, it is reported in literature [1] that the pumps may experience vibrations from magneto - hydrodynamic instability, especially at large flow rates. Online vibration monitoring of these pumps may be carried out using a specially designed vibration monitoring device consisting of a waveguide and accelerometer combination. The construction of the waveguide indicating locations for mounting accelerometers on these waveguide is shown in Fig. 1.

These waveguides have a conical end (Fig. 1) at which it is attached to the ALIP and these waveguides are to be attached under different orientations as shown in Fig. 2, but the configuration which would result in the most severe stresses is the one in which the horizontal axis of the waveguide is perpendicular to gravity (waveguides 2 and 3 in Fig. 2). The thickness of ALIP body where waveguide 2 is attached is $6 \mathrm{~mm}$ while at the location of attachment of waveguide 3 , thickness of ALIP body is $3 \mathrm{~mm}$. Hence, the configuration shown for waveguide 3 , being the most critical, has been analyzed.
} 



PLAN

Figure1: Details of waveguide and location of accelerometers



Figure 2: Location and orientation of waveguides on the ALIP body

The objective of this study is to estimate the fatigue life of the weld which is acted upon by stresses arising due to selfweight and excitation of its base. A suitable finite element model has been identified to carry out numerical simulation. Studies have been carried out to estimate the static stress at the weld arising due to self-weight of the waveguide. Natural frequency of the waveguide is found to ensure that it does not lie close to expected frequency of vibration of pump. A transient analysis is finally carried out to estimate the stress response of the weld under time varying displacements. The 
stress response obtained under time varying displacements is studied and it is utilized to estimate fatigue life of the weld using codal formula.

\section{Weld details and process of welding}

To obtain the higher frequencies signals, the waveguide must be attached to the component uniformly such that no air gap is present between them, as air gaps tend to reflect back the signals. To achieve a strong uniform attachment without air gaps, welding is considered to be most appropriate. The minimum thickness of the ALIP body, where the waveguide is to be attached is only $3 \mathrm{~mm}$, hence, a weld of size that is sufficient to provide enough strength with minimal distortion of the thin ALIP body is to be selected. Due to this reason, a $3 \mathrm{~mm}$ groove weld has been chosen to weld the waveguides to ALIP. Location of weld, waveguide and ALIP body is shown in Fig. 3.

Tungsten Inert Gas (TIG) welding is ideal to weld the waveguide end to ALIP body. The filler metal used for this welding shall be filler wire (Electrode Rod) ER316L conforming to SFA 5.9 of ASME Section II of Part C for SS 316L material. For initial passes, in which gap to be filled is less, filler wire having diameter $1.6 \mathrm{~mm}$ shall be used while the subsequent passes can be completed using $2.5 \mathrm{~mm}$ diameter filler wire. This welding shall be carried by qualified welder in accordance to Section IX of ASME. After completion of the weld, it will be properly ground followed by $100 \%$ Radiography and Liquid Penetrant Examination to ensure that the weld has no defects.

\section{DESIGN OF WAVEGUIDE}

\section{Material and dimensions of waveguide}

$\mathrm{C}$ hoice of material for construction of ALIP has been decided mainly based upon material's compatibility with sodium, temperature of operation, creep properties, economics etc. Keeping these criteria in mind for ALIP, the most appropriate material is (Stainless Steel) SS 316L or SS 304L [2]. In this study, it has been assumed that ALIP is constructed of SS $316 \mathrm{~L}$ and corresponding material properties have been selected from reference 3. Waveguides to be attached to ALIP is made of same material (SS 316L in this case) to facilitate similar metal weld.

The length of the waveguide is the result of a compromise between the temperatures required for proper functioning of accelerometers mounted at the extreme end of these waveguides and the displacement at that end due to vibrations. Whereas the temperature at the location of accelerometers in these waveguides should be close to the ambient temperature, the displacements due to vibration should be minimal. Use of insulation on the ALIP body also poses an additional limitation on the shortest length of the waveguide, which should be greater than insulation thickness. The diameter of the waveguide can vary depending upon space available for mounting the accelerometers. To meet these criteria, a $300 \mathrm{~mm}$ long waveguide has been chosen with diameter of $20 \mathrm{~mm}$ (Fig. 1).

\section{Determination of maximum stress under static condition}

The weld location of the waveguide is subjected to stresses as a result of attachment of the waveguide under the given orientation. The bending stress acting on the weld is given as:-

$$
\sigma_{\mathrm{b}}=\mathrm{M} / \mathrm{Z}
$$

where,

$$
\begin{array}{ll}
\sigma_{\mathrm{b}} & =\text { Bending stress } \\
\mathrm{M} & =\text { Moment due to self-weight at weld location } \\
\mathrm{Z} & =\text { Section modulus of the weld }
\end{array}
$$

The weight of waveguide is $0.9 \mathrm{~kg}$ and centre of mass is at a distance of $169 \mathrm{~mm}$ from tip of the weld; so,

$\mathrm{M} \quad=1.49 \mathrm{~N}-\mathrm{m}$

$\mathrm{Z} \quad=\mathrm{I} / \mathrm{y}=2.12 \times 10^{-8} \mathrm{~m}^{3}$

Hence, $\sigma_{\mathrm{b}} \quad=1.49 / 2.12 \times 10^{-8}=70 \mathrm{MPa}$

The effect of stress concentration factor has been neglected in the above calculation. The increment in stress due to this has been estimated using Finite Element Method (FEM).

\section{Finite element model}

Commercially available Finite Element Method (FEM) based code is used to carry out the numerical simulation. A complete solid model of the waveguide has been used as symmetry advantage could not be taken due to geometry and 
boundary conditions. The model is shown in Fig. 3. The portion of ALIP body selected for simulation is discussed under following section.

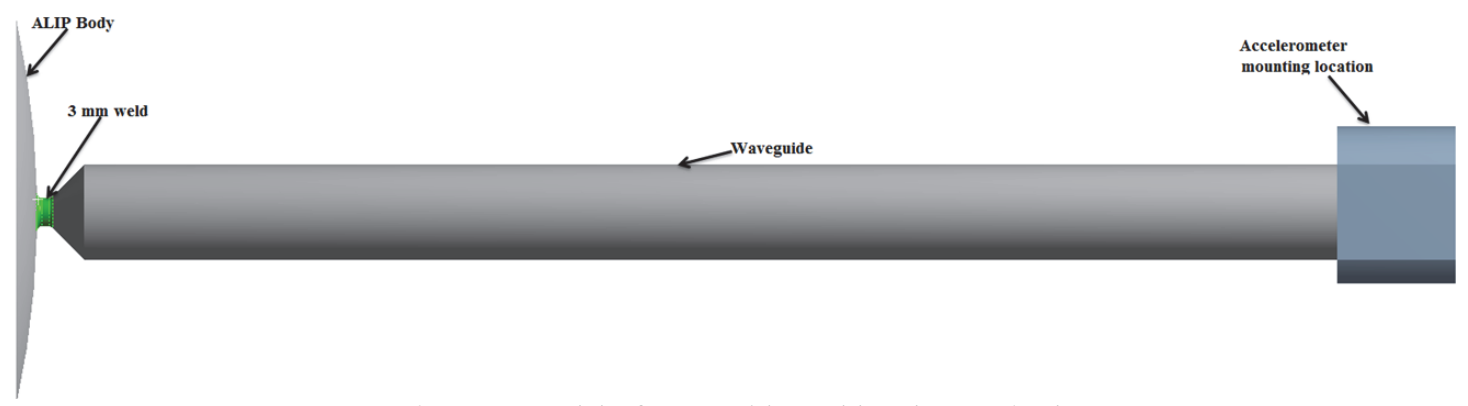

Figure 3: Model of waveguide, weld and ALIP body

This model is discretized using 10 node solid tetrahedral elements and mesh independent study has been carried out by refining the mesh near the weld location, until the difference in the result (maximum stress) between two consecutive trials was negligible. Using FEM, the maximum equivalent stress at the weld location has been found to be around 96 MPa. The deformed shape is shown in Fig. 4 while the detailed equivalent (von mises) stress around the weld is shown in Fig. 5.

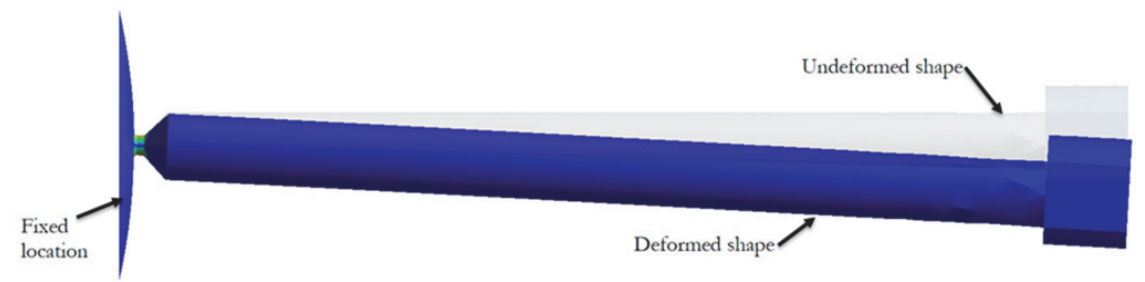

Figure 4: Deformed shape under self-weight of the waveguide

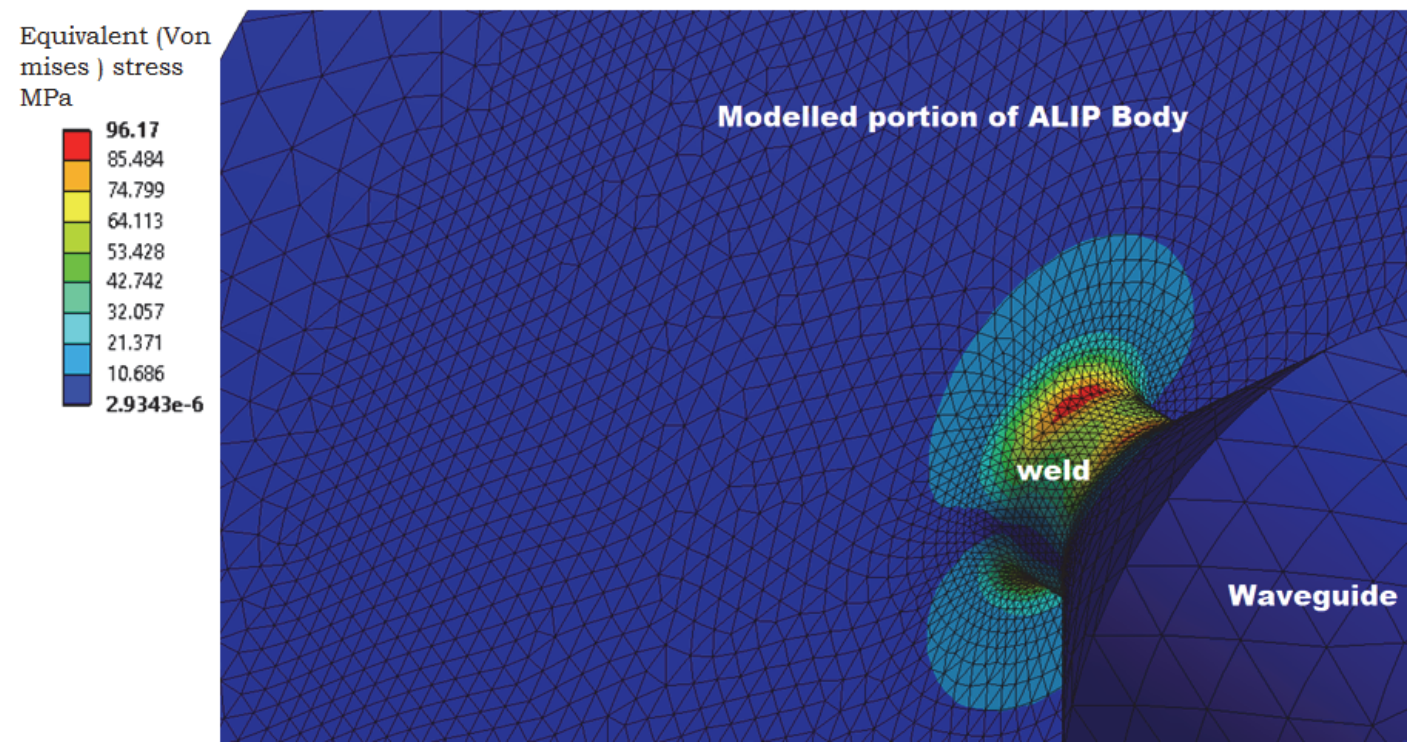

Figure5: Equivalent (von-mises) stress around the weld location due to self-weight of the waveguide

\section{MODELING OF ALIP BODY}

$t$ the point of attachment, the waveguide (waveguide 2 and 3) is oriented with its horizontal axis perpendicular to gravity as shown in Fig. 2. In order to carry out the analysis, instead of completely considering the entire ALIP body, only a small portion of the ALIP body has been considered. The size of this portion of the ALIP has been 
estimated with the concept of "Beam on Elastic Foundation" [4], such that the effect of attachment of waveguide on the ALIP body is negligible beyond this region. This region is represented approximately by a circle whose radius is equal to $1 / \beta .1 / \beta$ is the distance beyond the application of load after which factors like deflection, slope, bending moment, etc. are negligible [4].

$$
\beta=\sqrt[4]{\frac{3\left(1-v^{2}\right)}{r^{2} b^{2}}}
$$

where,

$$
\begin{array}{ll}
v & =\text { poisson ratio } \\
r & =\text { radius of curvature } \\
b & =\text { thickness }
\end{array}
$$

Substituting $v=0.3, \quad \beta=\frac{1.285}{\sqrt{r h}}$

For $\mathrm{r}=0.189 \mathrm{~m}$ and $\mathrm{h}=0.003 \mathrm{~m}, \beta=54 \mathrm{~m}^{-1}=0.054 \mathrm{~mm}^{-1}$

Hence, $1 / \beta=18.53 \mathrm{~mm}$

This is illustrated with the help of Fig. 6.

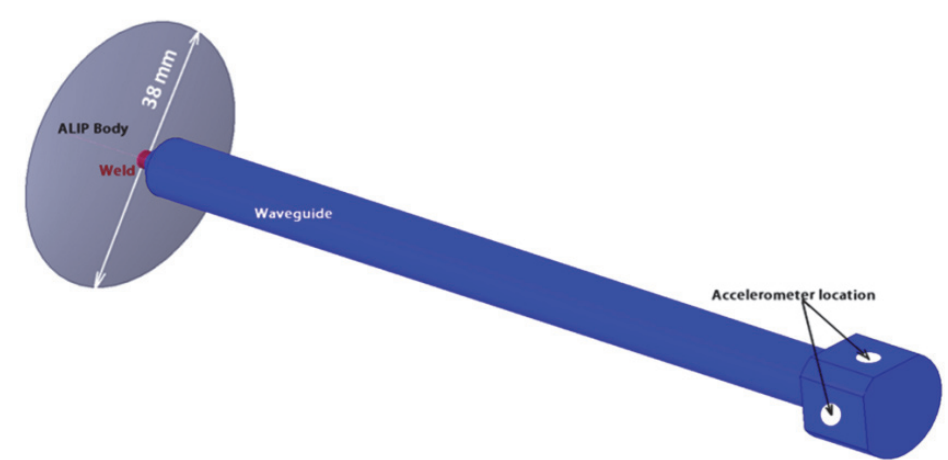

Figure 6: Isometric view of modeled ALIP body and waveguide attached with weld

\section{DYNAMIC ANALYSIS CARRIED ON MODEL}

7 he vibration in the ALIP sets the waveguide also into vibration and the welded region experiences maximum alternating stress cycles. To estimate the stresses under vibration, first of all, natural frequency of the waveguide has been estimated.

\section{Natural frequency of waveguide}

The waveguide consists of different cross-sections and hence, its natural frequency needs to be estimated using FEM. In order to confirm the correctness of the modeling exercise using FEM, the natural frequency of a simple cantilever of 20 $\mathrm{mm}$ diameter and length of $300 \mathrm{~mm}$ was calculated using analytical formula as well as using FEM analysis. The natural frequency of a cantilever beam is given by the formula 3 [5]:

$$
\omega_{n}=\left(\beta_{n} l\right)^{2} \times \sqrt{\frac{E \times I}{\rho \times l^{4}}}
$$

where,

$$
\begin{array}{ll}
\omega & =\text { Angular velocity/ frequency } \\
n & =\text { Mode number } \\
E & =\text { Young's modulus of the material } \\
l & =\text { Length of the cantilever }
\end{array}
$$


$I \quad=$ Moment of inertia

$\rho \quad=$ Mass per unit length

$\beta \quad=$ Number which depends on the boundary conditions of the problem

The value of $\left(\beta_{n} l\right)^{2}$ for a cantilever[5] is given in Tab. 1 .

\begin{tabular}{lll}
\hline$\left(\beta_{1} l\right)^{2}$ & $\left(\beta_{2} l\right)^{2}$ & $\left(\beta_{3} l\right)^{2}$ \\
3.52 & 22.0 & 61.7 \\
\hline
\end{tabular}

Table 1: Values of $\left(\beta_{n} l\right)^{2}$

For

$E \quad=2 \times 10^{11} \mathrm{~N} / \mathrm{m}^{2}$

l $\quad=0.3 \mathrm{~m}$

$I \quad=7.854 \times 10^{-9} \mathrm{~m}^{4}$

$\rho \quad=2.466 \mathrm{~kg} / \mathrm{m}$

$\omega_{1} \quad=987.07 \mathrm{rad} / \mathrm{s}=157.09 \mathrm{~Hz}$

$\omega_{2} \quad=6169.24 \mathrm{rad} / \mathrm{s}=981.86 \mathrm{~Hz}$

The natural frequencies determined by FEM are as follows,

$\omega_{1} \quad=156.97 \mathrm{~Hz}$

$\omega_{2} \quad=969.31 \mathrm{~Hz}$

This shows that the results obtained through FEM are in close agreement to that obtained using analytical method.

The actual $20 \mathrm{~mm}$ waveguide, as shown in Fig. 1, which has to be analyzed has a conical end where a $3 \mathrm{~mm}$ groove weld is present; hence the diameter at this location is $6 \mathrm{~mm}$. This change in cross-section results in decrease of the natural frequency, which has been estimated using FEM and is tabulated in Tab. 2.

\begin{tabular}{cc} 
Mode & Frequency $(\mathrm{Hz})$ \\
1 & 32.2 \\
2 & 567.7 \\
\hline
\end{tabular}

Table 2: Natural frequencies of vibration of waveguide

Fig. 7 and 8 shows the first two mode shapes of the waveguide

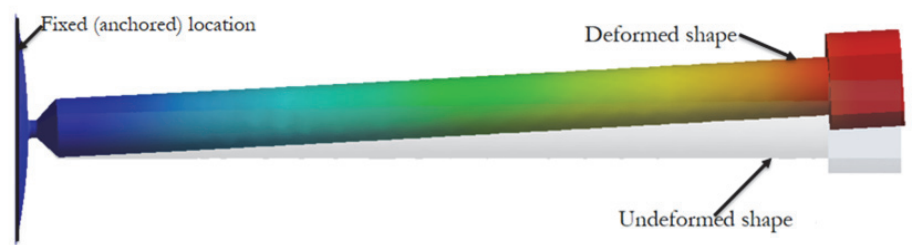

Figure 7: First mode shape of vibration of waveguide at $32.2 \mathrm{~Hz}$

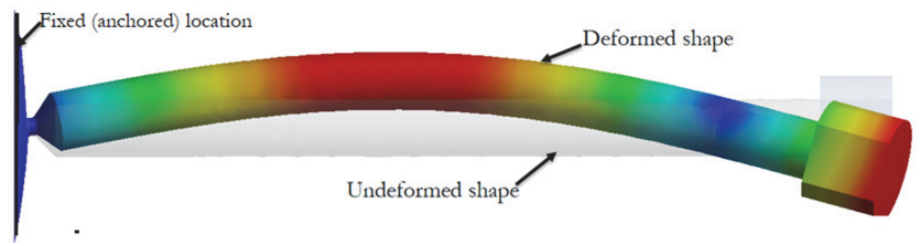

Figure 8: Second mode shape of vibration of waveguide at $567.7 \mathrm{~Hz}$

Reference 1 indicates that the dominant Low Frequency (LF) pressure pulsation lies in the range of $0-10 \mathrm{~Hz}$ and at an AC supply frequency of $50 \mathrm{~Hz}$, a Double Supply Frequency (DSF) pressure pulsation lies at $100 \mathrm{~Hz}$. These frequencies arising 
due to magneto-hydrodynamic instability lie far away from both the estimated natural frequency of the waveguide. Hence resonance of waveguide, which may lead to large amplitudes, is not expected during its operation.

Transient analysis at $10 \mathrm{~Hz}$ frequency:

Assuming that the vibration of ALIP sets the waveguide under harmonic vibration, the weld would be subjected to maximum stress cycle. To estimate these stresses, the modeled ALIP body was set under harmonic motion governed by Eqn. (4) in vertical direction.

\section{Displacement cycle}

The maximum acceleration (i.e. $0.5 \mathrm{~m} / \mathrm{s}^{2}$ ) and expected frequency of vibration (i.e. $10 \mathrm{~Hz}$ ) due to magneto-hydrodynamic instability has been chosen based on details given in Reference 1.

\section{Given}

Maximum acceleration

Frequency of vibration

Displacement equation,

$$
\begin{array}{ll}
\mathrm{a}_{\mathrm{o}}{ }^{\prime} & =0.5 \mathrm{~m} / \mathrm{s}^{2}=500 \mathrm{~mm} / \mathrm{s}^{2} \\
\mathrm{c}^{\prime} & =10 \mathrm{~Hz}=2 \pi \times 10 \mathrm{rad} / \mathrm{s} \\
\mathrm{y}^{\prime} & =\left(\mathrm{a}_{\mathrm{o}} / \omega^{2}\right) \sin (\omega \mathrm{t})
\end{array}
$$

Putting the numerical values,

$$
y=\frac{500}{(2 \pi \times 10)^{2}} \times \sin (2 \pi \times 10 \times \text { time }) \mathrm{mm}
$$

The effect of damping has been considered in obtaining the response of the system by incorporating a proportional damping 'C’ [6], as given by Rayleigh:

$$
\text { C }=\alpha M+\beta K
$$

where,

$\mathrm{M}$ is mass matrix and $\mathrm{K}$ is the stiffness matrix

$\alpha, \beta$ are constants which are related to natural frequency $\left(\omega_{\mathrm{i}}\right)$ and damping ratio $(\zeta)$ as,

$$
2 \zeta \omega_{\mathrm{i}}=\alpha+\omega_{\mathrm{i}}^{2} \beta
$$

The first two natural frequencies and damping of $2 \%$ for both frequencies are used for determining these damping constants. Six cycle of operation, as shown in Fig. 9 were given as input to the extreme left of the ALIP body at the location as shown in Fig. 10.

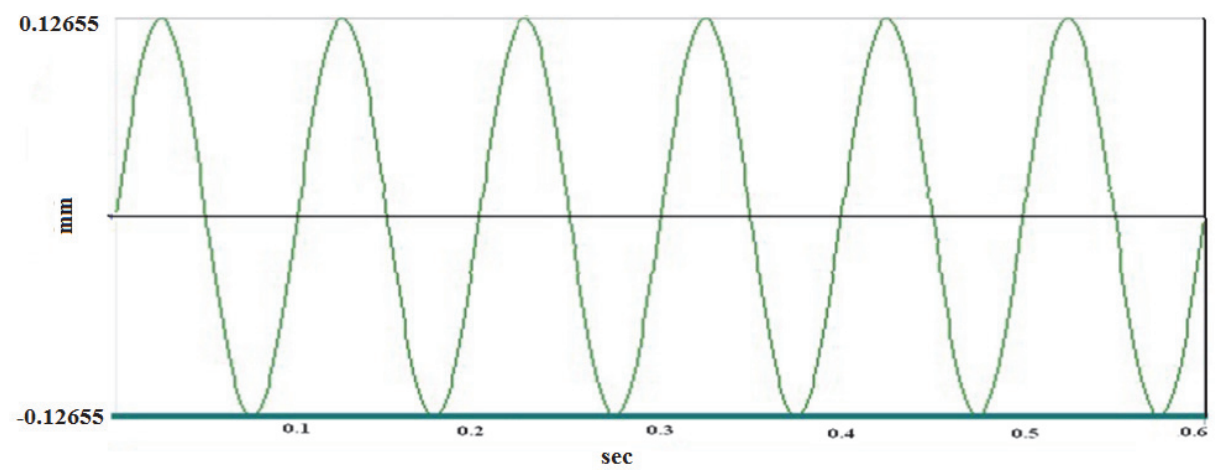

Figure 9: Input displacement cycles

Under these displacement cycle, given at the location as shown in Fig. 7, the maximum equivalent stress at a location in the weld region was obtained as a function of time and is shown in Fig. 11. 


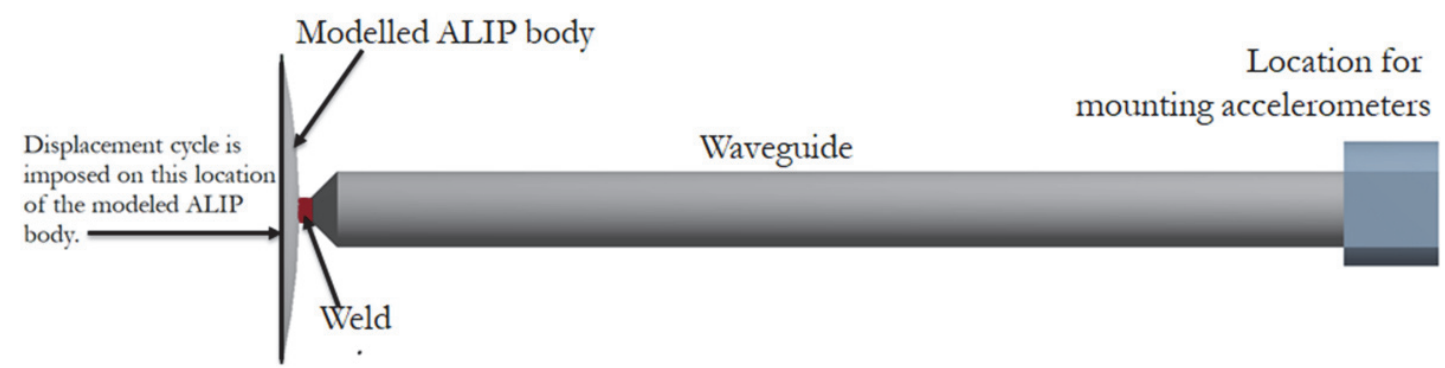

Figure 10: Location of input displacement cycle at the ALIP body

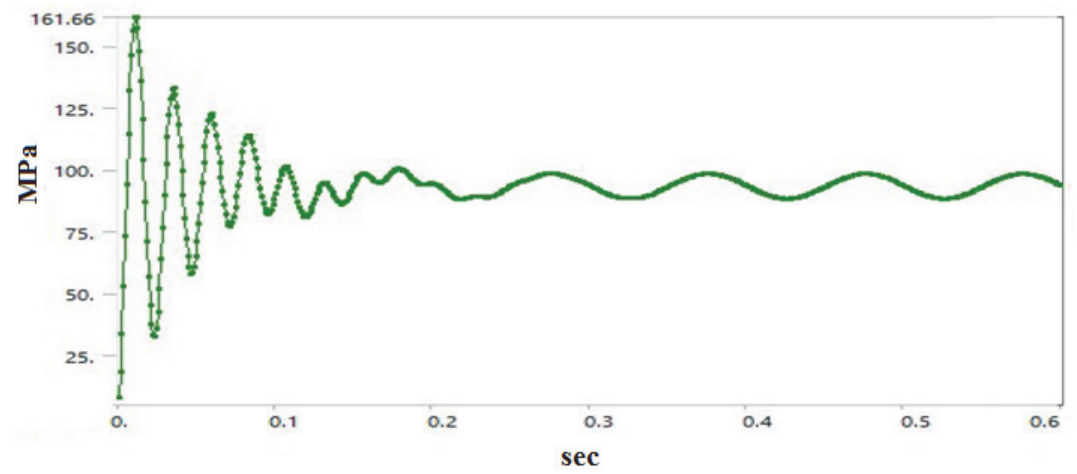

Figure 11: Variation of maximum equivalent stress at the weld location as a function of time

\section{Fatigue Life Estimation}

The stress cycles has an initial exponentially decaying amplitude region in which peak stress at the critically loaded location in the first cycle is $161.66 \mathrm{MPa}$. The eventual steady state stress cycle at the same location has alternating stress range $=10.6 \mathrm{MPa}$, about a mean stress of $93.3 \mathrm{MPa}$. Under such loading, in order to find the reliable period of operation, estimation of fatigue life of the weld is critical. In order to find out the fatigue life, ASME Section VIII Division 2 [7] has been used, which lays out the procedure for estimation of fatigue life of weld.

It is to be noted that the initial exponentially decaying stress amplitude corresponds to the solution of complementary part of the governing differential equation [6], which occurs during start up of ALIP. The number of cycles, hence calculated for this stress range would indicate the number of start up of ALIP which the weld can withstand. ALIP is supposed to operate continuously without shutdown for the incessant supply of sodium to purification circuit and to make up for various leakages and hence, it will not be shutdown unless there exists a need for maintenance.

The number of cycles, $N$ as per 2010 ASME Section VIII, Division 2, 3.F.2.2 for welded joint, is given as

$$
N=\frac{f_{I}}{f_{E}} \times\left(\frac{f_{M T} \cdot C}{\Delta S_{e s s, e}}\right)^{\frac{1}{b}}
$$

where,

$f_{I}=$ Fatigue improvement method correction factor for welded joint fatigue curve

this factor has been taken as 1 assuming that no fatigue improvement method has been used. If any improvement method is adopted then the factor can be changed as per formula given in reference 7 .

$f_{E}=$ Environmental correction factor to the welded joint fatigue curve

this factor is taken as 4 as per reference 7.

$f_{M T}=$ Material temperature correction factor

this is the ratio of modulus of elasticity of the material under evaluation at average temperature of cycle being evaluated to modulus of elasticity of carbon steel at ambient temperature.

$C, b=$ Given in Tab. 3.F.11 of ASME 2010 SECTION VIII, DIVISION 2

In this calculation $C$ is taken as 11577.9 considering Lower prediction interval (-3o) for design unless while $b$ is taken as 0.31950 . 
$\Delta S_{e s s, k}=$ Equivalent structural stress range parameter, given as

$$
\Delta S_{e s s, k}=\left(\frac{\Delta \sigma_{k}}{t_{e s s}^{\left(\frac{2-m_{s s}}{2 \cdot m_{s s}}\right)} \times I^{\frac{1}{m_{s s}}} \times f_{M, k}}\right)
$$

where,
$\Delta \sigma_{k} \quad=$ Stress range
$m_{s s} \quad=$ Exponent used in a fatigue analysis based on the structural stress
this factor has been taken as 3.6 as per reference 7
$t_{\text {ess }} \quad=$ Structural stress effective thickness
this factor has been taken as 16 as per reference 7
$I \quad=$ Correction factor used in the structural stress evaluation
$f_{M, k} \quad=$ Mean stress correction factor for the $\mathrm{k}^{\text {th }}$ cycle
The detailed procedure for estimation of these $I$ and $f_{M, k}$ is given in Reference 7.

The calculation given here corresponds to estimation of number of allowable cycles for the weld under constant stress amplitude, which has the following stress range,
Mean stress, $\sigma_{\text {mean }}$
$=93.3 \mathrm{MPa}$
Stress range, $\Delta \sigma_{\mathrm{k}}$
$=10.6 \mathrm{MPa}$
Number of cycles, $N \quad=2.247 \times 10^{8}$ cycles

i.e. the welded joint can withstand a continuous operation for 260 days, if it continues to vibrate at $10 \mathrm{~Hz}$ at room temperature.

In the next set of calculation, initial exponentially decaying stress response has been considered. For each cycle allowable number of cycles has been estimated and finally the number of overall cycles (i.e. maximum number of start up of ALIP which the weld can withstand) is arrived at, in such a way that total fatigue usage fraction remains less than one. Allowable cycles for each stress range are tabulated in Tab. 3.

\begin{tabular}{cccccc}
\hline Cycle No. & $\sigma_{\min }$ & $\sigma_{\max }$ & $\Delta \sigma$ & $\sigma_{\text {mean }}$ & Allowable no. of cycles \\
1 & 7.57 & 161.66 & 154.08 & 84.615 & 36967 \\
2 & 32.311 & 132.82 & 100.509 & 82.566 & 114980 \\
3 & 58.009 & 122.56 & 64.551 & 90.284 & 1651157 \\
4 & 77.205 & 114.0 & 36.795 & 95.6025 & 1275653 \\
5 & 82.115 & 101.30 & 19.185 & 91.707 & 7966562 \\
6 & 80.786 & 94.60 & 13.514 & 87.543 & 19726942 \\
7 & 86.03 & 98.521 & 12.491 & 92.275 & 22320979 \\
\hline
\end{tabular}

Table 3: Allowable cycles for various stress cycles during exponentially decaying period

Assuming the number of startups of ALIP $=n$

Calculation for total fatigue fraction to be less than 1 ,

$\frac{n}{36967}+\frac{n}{114980}+\frac{n}{1651157}+\frac{n}{1275653}+\frac{n}{7966562}+\frac{n}{19726942}+\frac{n}{22330979} \leq 1$

Hence, $\mathrm{n} \leq 26767$ cycles

Hence, the weld can withstand more than 25000 startups at a temperature of $200^{\circ} \mathrm{C}$. 


\section{REDUCTION IN LENGTH OF WAVEGUIDE}

7 he main purpose of waveguide is to transmit signal from the vibrating body to which it is attached at one end (ALIP in present case) to the accelerometer mounted at its other end. An insulation of thickness $150 \mathrm{~mm}$ covers the ALIP body, and hence, the minimum length of waveguide must be greater than this. Initially it has been proposed to use a $300 \mathrm{~mm}$ waveguide for which fatigue life has been estimated. With the objective of obtaining lower stresses and hence, higher fatigue life, a $200 \mathrm{~mm}$ long waveguide has been analyzed. This decrease in length is assumed to have no appreciable increase in the temperature at the accelerometer region as compared to original length.

\section{Analysis}

The bending stress at the weld location for $200 \mathrm{~mm}$ long waveguide was found to be $47.84 \mathrm{MPa}$, whereas the natural frequency of this waveguide is shown in following table:

\begin{tabular}{cc}
\hline Mode & Frequency $(\mathrm{Hz})$ \\
1 & 56.20 \\
2 & 876.21 \\
\hline
\end{tabular}

Table 4: Different mode shape frequency of the waveguide

\section{Stress due to vibration}

For finding out the stress response, 3 cycles were analyzed in this case at a frequency of $10 \mathrm{~Hz}$ and maximum amplitude of $0.5 \mathrm{~m} / \mathrm{s}^{2}$. The stress response is shown in the figure below.

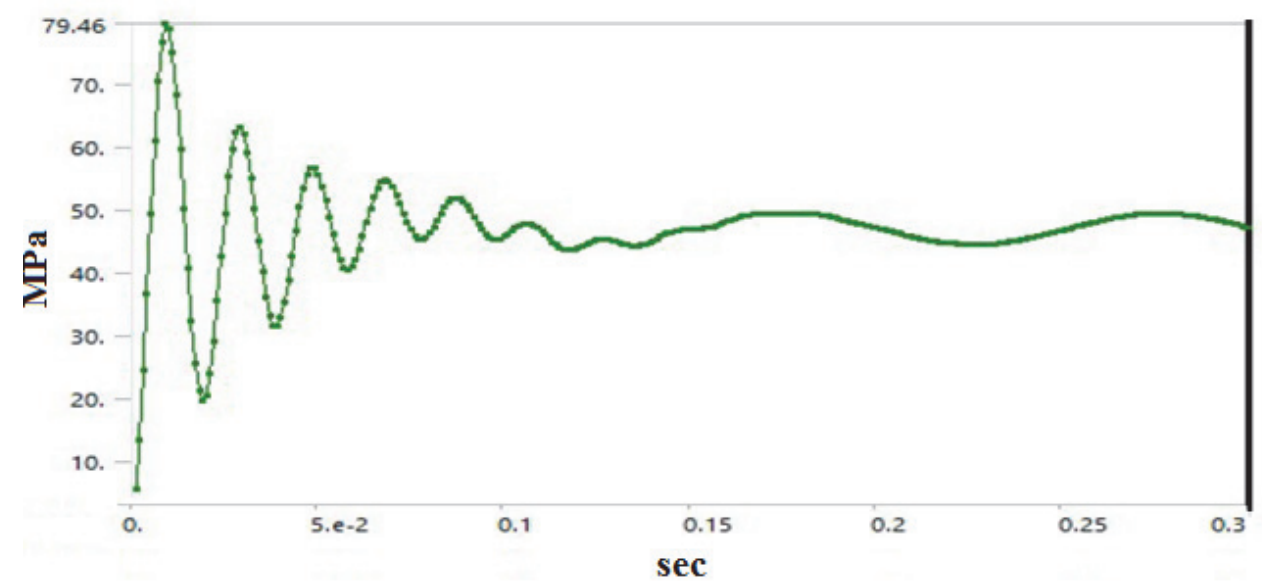

Figure 12: Stress at the weld location as a function of time

\section{Estimation of fatigue life of the weld}

In this case the mean stress has reduced to about $48 \mathrm{MPa}$ while the stress range has become $5.8 \mathrm{MPa}$. Under such condition and neglecting the exponentially decaying amplitude region the fatigue life of the weld has been estimated to be

$$
\mathrm{N}=1.483 \times 10^{9} \text { cycles }
$$

i.e. the welded joint can withstand a continuous operation for 1716 days or approximately $4.7 y e a r s$, if it continues to vibrate at $10 \mathrm{~Hz}$ at $200^{\circ} \mathrm{C}$.

With a decrease in stress range as well as mean stress the number of start up which the weld can withstand, due to initial exponentially decaying stress amplitude, would be higher than those calculated for $300 \mathrm{~mm}$ length. 
Response at $100 \mathrm{~Hz}$ frequency

A further estimation of fatigue life was done by exciting the ALIP body at $100 \mathrm{~Hz}$ to consider Double Supply Frequency (DSF) [1]. As the frequency of excitation is high, the analysis was run for about 30 cycles. A similar transient simulation was done as described earlier to estimate the transient stress response.

The mean stress in this case remains the same as earlier i.e. $\sim 48 \mathrm{MPa}$ while the stress range has reduced to $3.29 \mathrm{MPa}$. The fatigue life under the constant stress amplitude is,

$$
\mathrm{N}=8.784 \times 10^{9} \text { cycles }
$$

i.e. the welded joint can withstand a continuous operation for 1016 days or approximately 2.78 years, if it continues to vibrate at $100 \mathrm{~Hz}$ at $200^{\circ} \mathrm{C}$.

\section{CONCLUSION}

$\mathrm{T}$ he stress response obtained under the sinusoidal excitation given near the base comprises of two parts. In the first part, stress amplitudes are high and decreases exponentially with time and its frequency is equal to the natural frequency of the waveguide. This response is governed by solution of homogenous part of the governing differential equation and it limits the number of start-ups (or sudden transients) that the weld can withstand.

The second part, which is the solution of particular integral, is stabilized stress cycle with same frequency as the frequency of excitation. The stress amplitude in this region remains constant and hence it limits the time for which the weld can be continuously subjected to such vibrations.

It is evident that the fatigue life of the weld is the determining criteria for a reliable period of operation of the waveguide. The fatigue life of the weld has been estimated and the minimum fatigue life of weld for $300 \mathrm{~mm}$ long waveguide vibrating at $10 \mathrm{~Hz}$ continuously is around 260 days. In an attempt to enhance this fatigue life, a reduction in the overall length by $100 \mathrm{~mm}$ was done and its effect on stress and life were obtained. This modification leads to a reduction in the stress due to self-weight from $96 \mathrm{MPa}$ to $48 \mathrm{MPa}$. The constant stress range has reduced from $10.6 \mathrm{MPa}$ to $5.8 \mathrm{MPa}$ when the ALIP vibrates at $10 \mathrm{~Hz}$ thereby increasing the minimum fatigue life of the weld to 1716 days, however for $100 \mathrm{~Hz}$ frequency the life of the weld has been estimated as 1016 days under continuous operation. Hence, the use of a $200 \mathrm{~mm}$ long waveguide is a preferable choice.

\section{REFERENCES}

[1] Hideo, Araseki et.al. (2004). Magnetohydrodynamic instability in annular linear induction pump Part I. Experiment and numerical analysis, Nuclear Engineering and Design 227 (2004) 29-50

[2] Mannan, S.L. et. al. (April, 2003). Selection of Materials for Prototype Fast Breeder Reactor, Transactions- Indian Institute of Metals 56(2)

[3] Boiler and Pressure Vessel Code (BPVC) ASME (2013). II Materials Part D Properties (Customary)

[4] Harvey,John F. Theory and design of pressure vessels, Van Nostrand Reinhold Company, New York.

[5] Thomson,W. T. Theory of Vibration, CBS Publishers and Distributors, New Delhi, Third Edition.

[6] Rao, Singiresu S. (2004). Mechanical Vibrations, Pearson Education Pte. Ltd.

[7] Boiler and Pressure Vessel Code (BPVC) ASME (2010). SECTION VIII, DIVISION 2, Part 5, Fatigue Assessment of Weld-Elastic Analysis and Structural Stress. 